\title{
Manifestation of juxtaductal coarctation after surgical ligation of persistent ductus arteriosus in infancy
}

\author{
A. M. Elseed, Elliot A. Shinebourne, and Matthias Paneth \\ From the Departments of Paediatrics and Surgery, Brompton Hospital and Cardiothoracic Institute, London
}

Coarctation of the aorta was observed in 2 infants after surgical interruption of the ductus arteriosus. In a further 3 patients transient, but severe, upper limb hypertension in the postoperative period required antihypertensive therapy.

The relevance of these findings to the pathogenesis of juxtaductal coarctation is discussed and their surgical importance is stressed, as the situation can be easily corrected if recognized on the operating table.

Rudolph (1970) and Rudolph, Heymann, and Spitznas (1972) recently reported aortic obstruction becoming evident in neonates who at, or soon after, birth had no clinical evidence of coarctation. They suggested that while the ductus remained open it acted as a conduit bypassing the site of potential obstruction in the aortic lumen. With postnatal constriction, a pressure gradient developed at the junction of the aortic isthmus with the descending aorta, producing juxtaductal coarctation. They were able to simulate this experimentally in fetal lambs. The human counterpart of this experimental work, namely production of a pressure difference between ascending and descending aorta, after surgical interruption of the ductus, has not been adequately documented. The object of this paper is to describe the development of such a pressure difference in 2 infants who subsequently required resection of a localized juxtaductal coarctation. Transient upper limb hypertension developed in a further 3 infants after operation. The findings in the 5 patients are then considered in relation to the pathogenesis of coarctation (Shinebourne and Elseed, 1974) and surgical management of persistent ductus arteriosus in infancy.

\section{Case histories}

\section{Case I}

A baby girl, born on 4 August I97I, birthweight $2.3 \mathrm{~kg}$, was kept in a premature unit for 2 weeks. At 6 weeks there was onset of difficulty with feeding, associated with failure to gain weight. She was admitted to Brompton Hospital aged II weeks with heart failure and a cardiac murmur.

Received 15 February 1974
On examination the patient was not cyanosed. Respiratory rate was 50 to 60 a minute. Pulse rate was 150 a minute with bouncy peripheral pulses. Femoral pulses were normal and both dorsalis pedes pulses were felt. Blood pressure varied between 90 and I IO $\mathrm{mmHg}$ but was equal in both arms. The second heart sound was normally split and there was a grade $3 / 6$ pansystolic murmur maximal at the second and third left intercostal spaces. No diastolic murmurs were heard. The liver was $2 \mathrm{~cm}$ below the right subcostal margin. The other systems were normal.

Chest $x$-ray showed cardiac enlargement and increased pulmonary vascular markings.

Electrocardiogram showed an axis of $+90^{\circ}$, right bundle-branch block, and $\mathrm{T}$ wave inversion over $\mathrm{V}_{5}$ and V6.

A clinical diagnosis of ventricular septal defect and persistent ductus arteriosus was made.

Cardiac catheterization This confirmed the clinical diagnosis. The catheter passed from the right atrium into the right ventricle, the pulmonary artery, and repeatedly crossed a persistent ductus into the descending aorta. The ventricular septal defect was also crossed and the catheter passed via the left ventricle to the ascending aorta. There was no pressure gradient between the ascending and descending aorta. Pulmonary:systemic flow ratio $(\mathrm{Qp}: \mathrm{Qs})=\mathbf{3 \cdot 2}$ : r. Pulmonary artery pressure was $30 \mathrm{mmHg}$ below systemic level. Left ventricular angiogram showed a moderate sized ventricular septal defect and slight narrowing of the aortic isthmus distal to the left subclavian artery (Fig. I). Closure of the ductus arteriosus and banding of the pulmonary artery were advised and uneventfully carried out. The ductus was found to be short and very wide and the aorta in the region of the ductus appeared normal on external examination.

Postoperative course Two hours after ductal closure blood pressure increased from I IO to $170 \mathrm{mmHg}$ and 


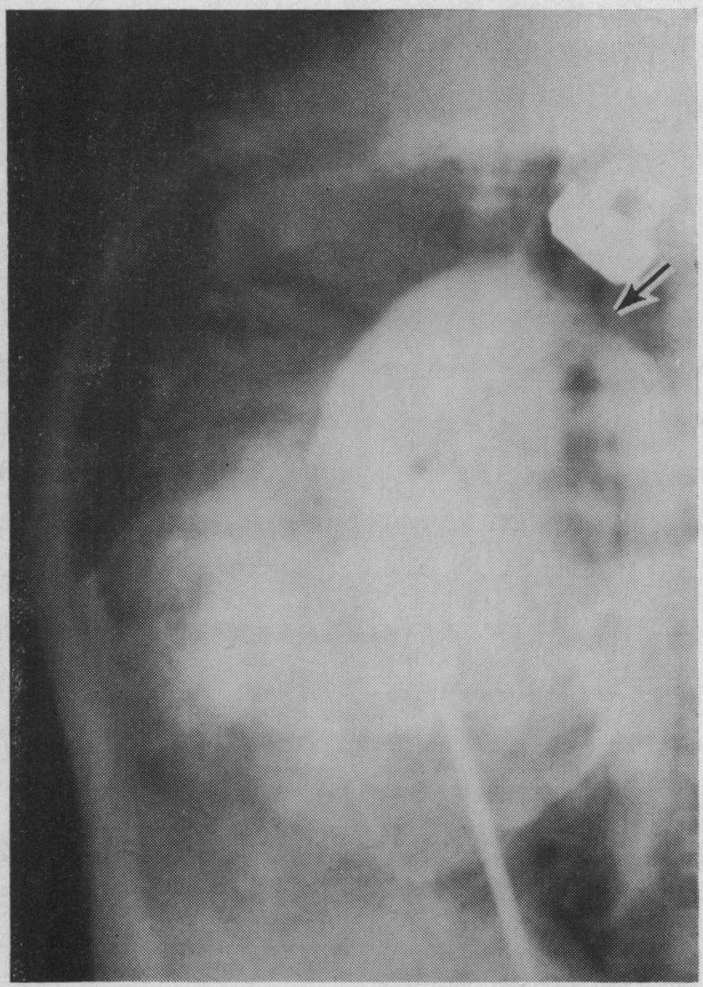

FIG. I Angiogram (lateral view) to demonstrate aortic anatomy in Case I before surgical interruption of persistent ductus arteriosus. Narrowing of the isthmus is demonstrated but there is no evidence of coarctation.

eventually settled around $120 \mathrm{mmHg}$ in the right arm and 90 to $100 \mathrm{mmHg}$ in the left arm (Doppler shift technique: Elseed, Shinebourne, and Joseph, 1973). The patient was mechanically ventilated for 14 hours after operation and then extubated. Four days later the patient showed sudden deterioration and developed severe heart failure. Femoral pulses, which were normal before operation, were difficult to palpate, and response to antifailure therapy was poor. Repeat cardiac catheterization was performed to confirm the clinical diagnosis of coarctation.

Cardiac catheterization This confirmed the presence of coarctation with a gradient across it of $20 \mathrm{mmHg}$ under general anaesthesia. An aortogram showed severe coarctation below and involving the origin of the left subclavian artery (Fig. 2). The coarctation was resected and after operation femoral pulses were normal.

\section{Case 2}

A baby girl, born 9 July I97I, birthweight $2.6 \mathrm{~kg}$. There were no immediate neonatal problems. A cardiac murmur was heard at the age of 2 weeks. Apart from slow weight gain, the patient remained asymptomatic. She

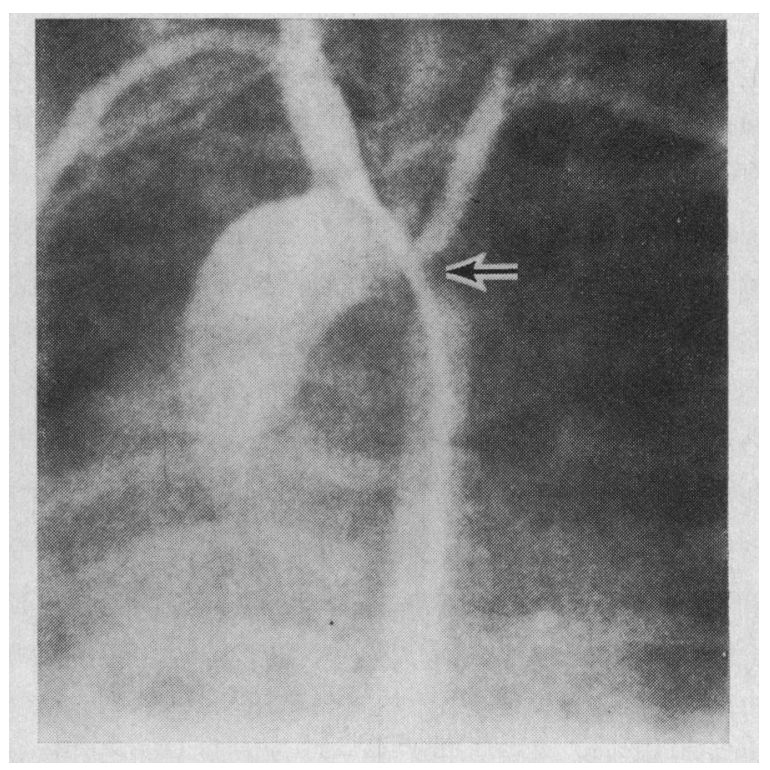

FIG. 2 Aortogram (left anterior oblique view) in Case I to demonstrate localized juxtaductal coarctation (arrow) which became apparent after surgical interruption of persistent ductus arteriosus.

was admitted for elective cardiac catheterization at the age of 14 months. Examination showed she was below 3 rd centile for weight and height. There was no cyanosis. Peripheral pulses were all palpable and of good volume. Blood pressure was II5/60 mmHg (Doppler technique) in the upper and lower limbs. The second heart sound was normally split and $\mathbf{P}_{\mathbf{2}}$ accentuated. There was a continuous murmur below the left clavicle and a grade $4 / 6$ pansystolic murmur at the third left intercostal space. The other systems were normal.

Chest $x$-ray showed cardiac enlargement and increased pulmonary vascular markings.

Electrocardiogram showed an axis of $+100^{\circ}$ and biventricular hypertrophy.

Cardiac catheterization This showed an increase in $\mathrm{O}_{2}$ saturation at right ventricular level. The catheter passed from the pulmonary artery through a persistent ductus arteriosus to the descending aorta. Pulmonary artery pressure was at systemic level. Qp:Qs=r.7:I. No pressure difference was shown between the ascending and descending aorta. An aortogram showed a persistent ductus arteriosus and an abnormal indentation of the posterior wall of the aorta directly opposite the ductus (Fig. 3). Left ventricular cineangiogram showed a ventricular septal defect. Surgical interruption of the ductus was advised.

At operation the ductus, which was the size of the upper segment of the aorta, was divided and after both ends had been sutured, the aorta below the ductus was noted to be non-pulsatile. The pressure in the descending aorta showed little phasic difference between systole and diastole, the mean pressure being $75 \mathrm{mmHg}$ (Fig. 4). 


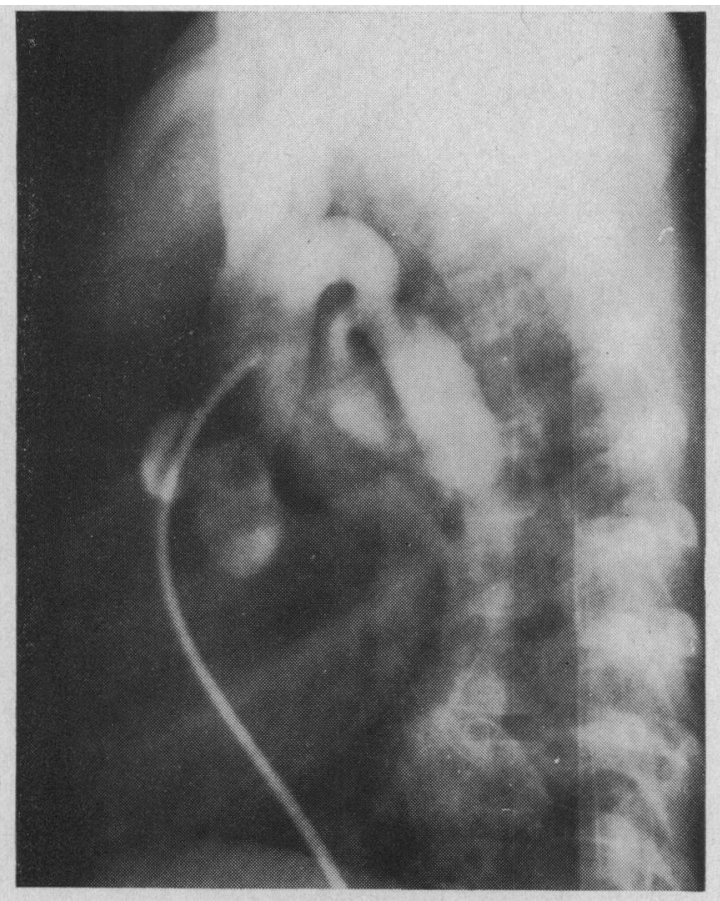

FIG. 3 Aortogram (lateral view) in Case 2 demonstrating persistent ductus arteriosus, isthmal narrowing, and indentation on the posterior aortic wall opposite the ductal attachment. No pressure difference was detected between ascending and descending aorta at cardiac catheterization.
A normal arterial wave form was found in the ascending aorta where the mean pressure was $100 \mathrm{mmHg}$. As an obstruction to aortic flow appeared to have developed, the aortic segment opposite the point where the ductus was attached was occluded between clamps, excised, and end-to-end anastomosis performed. Normal pulsation was then restored to the lower aortic segment (Fig. 4). The patient had a smooth postoperative recovery and was discharged from hospital ro days later.

\section{Case 3}

A baby girl, born 17 August 1971, birthweight $2.2 \mathrm{~kg}$, had a cardiac murmur which was heard at birth and developed congestive heart failure shortly after. She was put on antifailure therapy with good response, and was referred to Brompton Hospital at the age of I I months.

On examination she v'as pink. All peripheral pulses were collapsing. Blood pressure was $105 / 50 \mathrm{mmHg}$. The second sound was split with normal $\mathrm{P}_{2}$. A continuous murmur was heard below the left clavicle. There were no other abnormal findings.

Chest $x$-ray showed cardiac enlargement and increased pulmonary vascular markings.

Electrocardiogram showed an axis of $+60^{\circ}$ and inversion of $\mathrm{T}$ waves over $\mathrm{V}_{5}$ and V6 indicating left ventricular strain.

A clinical diagnosis of persistent ductus arteriosus was made and the patient was referred for operation. The ductus was divided and sutured. Upper limb blood pressure was $130 / 70 \mathrm{mmHg}$ immediately after return to the intensive care unit. Thirty minutes later upper limb blood pressure increased to $190 / \mathrm{r}_{30}$ $\mathrm{mmHg}$. Femoral pulses were present and lower limb blood pressure was $100 \mathrm{mmHg}$ systolic. The upper limb hypertension persisted for over an hour and increased

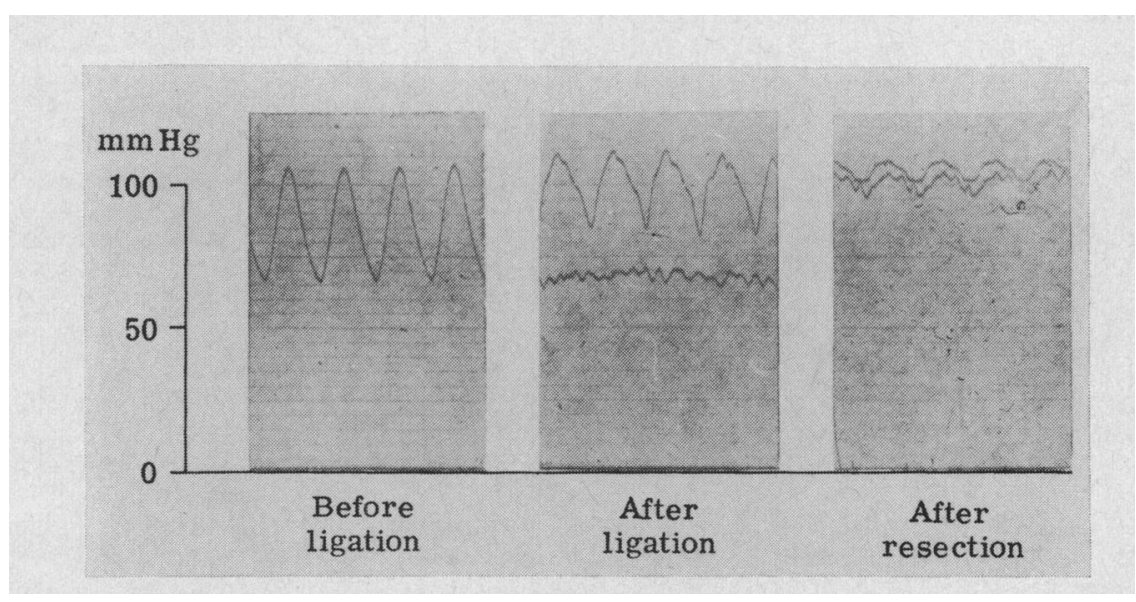

FIG. 4 Aortic blood pressures recorded during operation in Case 2. The pressure tracing before ductal closure was identical above and below the ductus. After ductal closure the aortic pressure proximal to the ductus (upper tracing) remained constant while descending aortic pressure (lower tracing) fell. The phasic difference between systole and diastole was reduced. With resection of the coarctation descending aortic pressure approximated to that in the ascending aorta. 
to $200 / 140 \mathrm{mmHg}$ while the lower limb blood pressure stayed around $100 \mathrm{mmHg}$. The patient was given intravenous diazepam and the blood pressure fell to $160 / 100$ mmHg over the next few days. The upper limb blood pressure gradually dropped further to $100 \mathrm{mmHg}$ on the 6th postoperative day. The patient was discharged 2 days later when the blood pressure was $100 \mathrm{mmHg}$ in both upper and lower limbs.

\section{Case 4}

A baby boy, born I2 March 1972, had a cardiac murmur which was heard on incidental examination. He was referred to Brompton Hospital at the age of 8 months. There were no other symptoms.

On examination the patient was pink. Peripheral pulses were normal and all were palpable. Blood pressure was $90 \mathrm{mmHg}$ systolic in upper limbs. There was a split second heart sound and a continuous murmur under the left clavicle. The other systems were normal.

Chest $x$-ray showed cardiac enlargement with increased pulmonary vascular markings.

Electrocardiogram showed an axis of $+60^{\circ}$ There was no evidence of ventricular hypertrophy.

A clinical diagnosis of persistent ductus arteriosus was suggested and confirmed at cardiac catheterization. $Q p: Q s=2 \cdot 6: I$. There was no pressure difference between ascending and descending aorta and a ventricular septal defect was excluded.

At operation a large ductus was divided and sutured. Immediately after return to the ward blood pressure in the upper limbs was $120 / 70 \mathrm{mmHg}$ while lower limb blood pressure was $90 \mathrm{mmHg}$ systolic. One hour later upper limb blood pressure increased to $140 / 90 \mathrm{mmHg}$ and rose to $170 / 130 \mathrm{mmHg} 12$ hours after operation. Femoral pulses were palpable and lower limb blood pressure was still $90 \mathrm{mmHg}$. Large doses of diazepam and papaveretum had to be given before the blood pressure started to fall, eventually settling around 140/90 $\mathrm{mmHg}$. On the third postoperative day the blood pres- sure was $\mathrm{I}$ 10 $\mathrm{mmHg}$ systolic in the upper limbs and 85 $\mathrm{mmHg}$ in the lower limbs.

\section{Case 5}

A baby boy, born 4 June 1973, had congestive heart failure at 2 weeks of age. He was treated with antifailure therapy, and referred for cardiac catheterization aged 3 weeks. Examination revealed respiratory rate of 70 a minute. He was pink. All peripheral pulses were felt. Blood pressure in the upper limbs was $110 \mathrm{mmHg}$ and in the lower limbs $80 \mathrm{mmHg}$ systolic. Grade $4 / 6$ pansystolic murmur maximal at the third left intercostal space.

Chest $x$-ray showed cardiac enlargement and increased pulmonary vascular markings.

Electrocardiogram showed right ventricular hypertrophy.

Cardiac catheterization Systolic pressures were equal in the right ventricle, left ventricle, aorta, and pulmonary artery. A persistent ductus arteriosus was crossed. No pressure difference was noted in aorta above and below the ductus. Angiographic appearances were of ventricular septal defect, and persistent ductus arteriosus, with no evidence of coarctation.

Surgical interruption of the persistent ductus arteriosus and banding of pulmonary artery were uneventful. Systolic blood pressure in the upper limbs was $90 \mathrm{mmHg}$ immediately after operation but rose to I $70 \mathrm{mmHg} 2$ hours later. Lower limb blood pressure measured simultaneously was $40 \mathrm{mmHg}$ systolic and the femoral pulses were difficult to palpate. Intravenous diazepam and chlorpromazine were given and the upper limb blood pressure came down to Iro to $120 \mathrm{mmHg}$. Over the following 4 days lower limb blood pressure increased to 80 to $90 \mathrm{mmHg}$ while the upper limb blood pressure remained at 110 to $120 \mathrm{mmHg}$. The patient remained in congestive heart failure and repeat

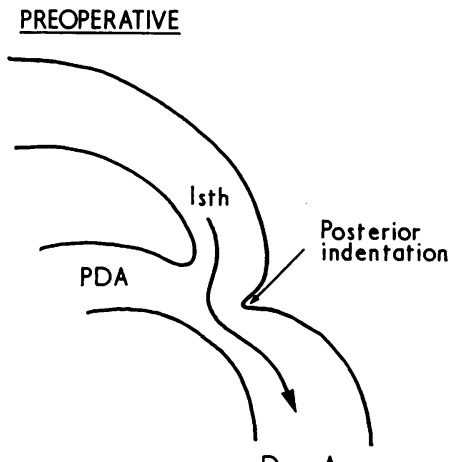

Desc. Ao

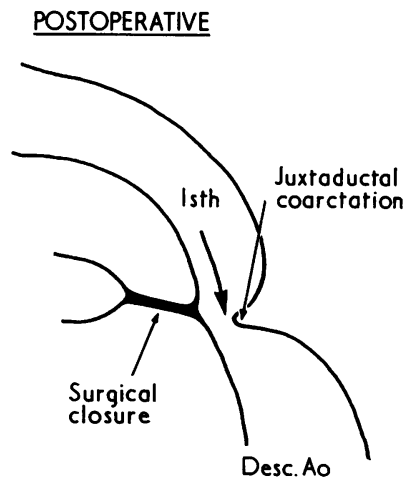

FIG. 5 Diagram of the proposed mechanism for manifestation of juxtaductal coarctation after surgical ductal closure. Preoperatively the persistent ductus acts as a conduit bypassing the site of potential obstruction produced by the posterior indentation projecting into the aortic lumen. After closure of the ductus this conduit no longer exists and the presence of juxtaductal coarctation becomes manifest by a pressure difference between ascending and descending aorta. 
cardiac catheterization was carried out. This showed a gradient of $20 \mathrm{mmHg}$ between ascending and descending aorta and the aortogram showed pronounced isthmal narrowing. The patient needed prolonged intermittent and continuous positive pressure ventilation in addition to intensive antifailure therapy. He was eventually discharged in good condition.

\section{Discussion}

As early as I84I Craigie described aortic obstruction at a fixed point, 'viz where the ductus arteriosus, converted into a ligament joins the aorta'. He suggested that aortic obstruction was caused by extension into the aorta of the same process that caused ductal closure. The Skodaic hypothesis (1893) later endorsed by Brom (1965) suggested that development of coarctation was related to constriction of ectopic ductal tissue situated in the aortic wall. More recently, Wielenga and Dankmeijer (1968) reported the presence of such ectopic ductal tissue encircling the aorta precisely at the site of coarctation, i.e. opposite the ductal attachment. These findings could not be confirmed by other workers, and Edwards et al. (1948) and later Hutchins (I97I) were unable to recognize abnormal or ectopic ductal tissue near the zone of coarctation. Rudolph et al. (1972) pointed out that if extension of ductal tissue into the aorta occurred, such tissue would have to be contiguous with the ductus and would least likely be located opposite the ductal attachment. Development of coarctation of the aorta after surgical interruption of the ductus as described in the first 2 infants cannot be explained by the Skodaic hypothesis and we suggest that our findings in these infants support the haemodynamic explanation for coarctation proposed by Rudolph et al. (1972) and Shinebourne and Elseed (1974). These workers consider that the dimensions of the aortic system at birth have been determined by flow patterns through them in the latter part of fetal life. The aortic isthmus is narrower than both ascending and descending aorta in the newborn. The junction of isthmus with descending aorta is represented by an indentation on the posterior aortic wall opposite the ductus and it is an exaggeration of this indentation which causes the shelf-like localized juxtaductal obstruction demonstrated anatomically by Edwards et al. (1948) and Hutchins (197r).

In fetal life and as long as an adequate ductus persists postnatally, there will be no obstruction to aortic flow as blood can readily pass from ascending to descending aorta by traversing the anterior aortic segment and aortic end of the duct which thus acts as a conduit. With ductal constriction and closure of the aortic end of the ductus, obstruction becomes apparent. This was thought to be the case in the 2 patients (Cases $I$ and 2 ) in whom coarctation of the aorta was detected after surgical closure of the ductus. Panagopoulos et al. (197I) described 4 children who developed coarctation of the aorta after surgical interruption of the ductus and we think this may be the mechanism responsible (Fig. 5).

The last three patients described in this report had transient upper limb hypertension after duct closure with definite pressure differences between upper and lower limbs. Taylor et al. (I950) reported I5 patients in whom, after surgical ligation of the ductus, there was an increase in direct systolic and diastolic pressures recorded from the radial artery. Keith, Rowe, and Vlad (1965) also reported an increase in systemic pressure after duct ligation and in some of their patients blood pressure reached alarming heights before returning to normal levels several days later. There was no mention of lower limb blood pressure or femoral pulses in either series.

A similar mechanism could have produced the large pressure difference between upper and lower limbs. Upper limb hypertension was not produced immediately the ductus was closed and we think this is because the aortic end of the ductus initially still provided a conduit. When this part of the ductus constricts a few hours later obstruction develops. The subsequent disappearance of upper limb hypertension may be explained by remodelling of the aorta with the establishment of normal patterns of flow in the aorta.

Coarctation of the aorta is diagnosed when lower limb pulses and/or pressures are reduced when compared to those in the upper limbs. In the patients described in this report lower limb pulses were normal preoperatively and in the 3 patients where ascending and descending aortic pressures were measured at cardiac catheterization no pressure difference was found.

In the presence of a large ductus arteriosus, coarctation of the aorta cannot be diagnosed clinically since the persistent ductus arteriosus masks the clinical features of coarctation. This should be borne in mind when surgical interruption of the ductus is performed in neonates and infants. During the operation attention should be paid to the lower aortic segment. If pressure within it falls, then 'acquired' coarctation of the aorta should be considered which may require resection. This 'acquired' coarctation may even involve the origin of the left subclavian artery as was demonstrated in the first patient.

The case histories are presented chronologically and reflect increasing awareness of the possibility of producing acquired juxtaductal coarctation. Our present policy in neonates and infants is to measure pressures at operation above and below the per- 
sistent ductus before and after closure. In this way the small residual mortality from ductal closure may be further lowered as surgically acquired coarctation can be dealt with immediately.

Our thanks are due to Dr. M. C. Joseph for information relating to patients under his care, Mr. C. Lincoln who performed the operation on Case 2, and Dr. R. H. Anderson for discussion of the manuscript.

\section{References}

Brom, A. G. (1965). Narrowing of the aortic isthmus and enlargement of the mind. Fournal of Thoracic and Cardiovascular Surgery, 50, 166.

Craigie, D. (I84I). Instance of obliteration of the aorta beyond the arch, illustrated by similar cases and observations. Edinburgh Medical and Surgical fournal, 56, 427.

Edwards, J. E., Christensen, N. A., Clagett, O. T., and McDonald, J. R. (1948). Pathologic considerations in coarctation of the aorta. Proceedings of Staff Meetings of the Mayo Clinic, 23, 324.

Elseed, A. M., Shinebourne, E. A., and Joseph, M. C. (1973) Assessment of techniques for measurement of blood pressure in infants and children. Archives of Diseases in Childhood, 48, 932.

Hutchins, G. M. (I97I). Coarctation of the aorta explained as a branch-point of the ductus arteriosus. American fournal of Pathology, 63, 203.
Keith, J. D., Rowe, R. D., and Vlad, P. (1967). Heart Disease in Infancy and Childhood, 2nd ed., p. 204. Macmillan, New York.

Panagopoulos, Ph. G., Tatooles, C. J., Aberdeen, E., Waterston, D. J., and Bonham-Carter, R. E. (1971). Patent ductus arteriosus in infants and children: a review of 936 operations. Thorax, 26, 137.

Rudolph, A. M. (1970). The changes in the circulation after birth. Their importance in congenital heart disease. Circulation, 41, 343.

Rudolph, A. M., Heymann, M. A., and Spitznas, U. (1972). Hemodynamic considerations in the development of narrowing of the aorta. American fournal of Cardiology, 30, 5 I4.

Skoda, J. quoted by Hochhaus, H. (1893). Ueber das Offenbleiben des Ductus Botali. Deutsches Archiv für klinische Medizin, 5I, I.

Shinebourne, E. A., and Elseed, A. M. (1974). Relation between fetal flow patterns, coarctation of the aorta, and pulmonary blood flow. British Heart fournal, 36, 492.

Taylor, B. E., Pollack, A. A., Burchell, H. B., Clagett, O. T., and Wood, E. H. (1950). Studies of the pulmonary and systemic arterial pressure in cases of patent ductus arteriosus with special reference to effects of surgical closure. fournal of Clinical Investigation, 29, 745.

Wielenga, G., and Dankmeijer, J. (1968). Coarctation of the aorta. Fournal of Pathology and Bacteriology, 95, 265.

Requests for reprints to Dr. Elliot A. Shinebourne, Brompton Hospital, Fulham Road, London SW $36 \mathrm{HP}$ 